\title{
Bento Rodrigues e a memória que a lama não apagou: o despertar para o patrimônio na (re)construção da identidade no contexto pós-desastre
}

\section{Bento Rodrigues and the memory that the mud did not erase: the awakening to heritage in the (re)construction of identity in the post-disaster context}

\author{
André Fabrício Silval 1 | Priscila Faulhaber" \\ Universidade Federal do Estado do Rio de Janeiro. Rio de Janeiro, Rio de Janeiro, Brasil \\ "Museu de Astronomia e Ciências Afins. Rio de Janeiro, Rio de Janeiro, Brasil
}

\begin{abstract}
Resumo: O presente artigo tem por objetivo debruçar-se, a partir do desastre ocorrido em 2015 no subdistrito de Bento Rodrigues, na cidade de Mariana, em Minas Gerais, em como a ideia de patrimônio é usada para construir, reconstruir e negociar as identidades, os valores e os significados sociais e culturais no contexto pós-desastre. Sob uma perspectiva que se baseia no entrecruzamento de emoções patrimoniais, usos do patrimônio, nostalgia do patrimônio e lugares de memória, busca-se apreender de que maneira essas noções se configuram nas ações de luta por reparação que se estabeleceram a partir do desastre. Consideramos esses elementos constituintes fundamentais para compreender como a comunidade de Bento Rodrigues se mobilizou a partir de um entendimento de patrimônio despertado pela perda do território e concebido como mecanismo de reivindicação de direito à memória.
\end{abstract}

Palavras-chave: Bento Rodrigues. Patrimônio. Memória e identidade. Desastre.

Abstract: This work aims to examine, from the disaster that occurred in 2015 in Bento Rodrigues, in the city of Mariana-MG, how the idea of heritage is used to construct, reconstruct, and negotiate identities, values, social and cultural meanings in the post-disaster context. From a perspective of intersection of heritage emotions, uses of heritage, nostalgia of heritage and places of memory, the purpose is to apprehend in what way these notions are configured in the actions of struggle for remediation that established from the disaster. We consider all these elements as fundamental components for the knowledgee of how the community of Bento Rodrigues mobilized from an understanding of heritage awakened by the loss of territory and conceived as a mechanism for claiming the right to memory.

Keywords: Bento Rodrigues. Heritage. Memory and identity. Disaster.

Silva, A. F., \& Faulhaber, P. (2020). Bento Rodrigues e a memória que a lama não apagou: o despertar para o patrimônio na (re)construção da identidade no contexto pós-desastre. Boletim do Museu Paraense Emílio Goeldi. Ciências Humanas, 15(1), e20200126. doi: 10.1590/2178-2547-BGOELDI-2019-0126.

Autor para correspondência: André Fabricio Silva. Universidade Federal do Estado do Rio de Janeiro. Av. Pasteur, 296 - Urca. Rio de Janeiro, RJ, Brasil. CEP 22290-240 (andrefabricio.ufop@gmail.com).

Recebido em 05/11/2019

Aprovado em 20/01/2020 


\section{INTRODUÇÃO}

Um amplo debate tem se estabelecido sobre o conceito de atingidos no Brasil. É uma categoria em disputa, cuja noção central, conforme aponta Vainer (2008), é determinada pelo processo de reconhecimento de um grupo social específico, família ou indivíduo, como atingido por empreendimentos cujo reconhecimento legal estabelece algum tipo de ressarcimento ou indenização, reabilitação ou reparação (Vainer, 2008). Tal categoria surge em meio ao grande número de barragens construídas no Brasil a partir da década de 1950, para atender à crescente demanda de produção de energia elétrica, culminando na construção de diversas usinas hidrelétricas no território brasileiro (Silva \& Silva, 2011).

Esse empreendimento visa à apropriação e à reprodução dos espaços sob a lógica desenvolvimentista e exploratória dos recursos naturais, não levando em conta as populações que habitam esses espaços e as relações de afetividades materiais e imateriais que envolvem toda a prática da territorialização. Nessa dinâmica, a população atingida pode ser entendida pela mesma concepção de identidade coletiva, a de atingidos por barragens, que se caracteriza pela perda de terras para o empreendimento, cujo resultado é o deslocamento do espaço de sociabilidade estabelecido (M. Santos, 2015).

Embora essa categoria esteja ligada à concepção, à implantação e à operação de projetos hidrelétricos, ela representa uma categoria social em disputa. Para Vainer (2008), a noção de atingido varia no tempo e no espaço, conforme o contexto político e cultural. Nesse sentido, ampliamos a noção de atingido para compreendê-lo não só a partir do impacto da remoção 'planejada', mas também a partir da lógica do desastre envolvendo barragens. Pensado como um dos 'estados possíveis do real', o desastre é definido como um ". . . acontecimento que desorganiza a ordem social, cultural, econômica e política de uma coletividade, a ponto de que esta não é capaz de reorganizar-se de forma espontânea e autônoma" (Taddei, 2016).
As pessoas comumente denominadas de atingidas, dentro do espectro da tragédia, enfrentam uma situação limite de abandono do território, sendo obrigadas a abdicarem de suas terras, de seus costumes e de suas tradições. São forçadas não somente a se adaptarem a uma nova realidade e a um novo lugar, mas também a reconstruírem seus laços familiares e sociais em um novo território. De acordo com Haesbaert (2004), o território seria um lugar dotado de territorialidade marcada por um caráter de apropriação sobre determinado local. Nesse sentido, o território é visto como simbólico e com valor de uso como espaço de trocas de afetos. Haesbaert (2004) afirma, pois, que o território envolve sempre ao mesmo tempo uma dimensão simbólica, cultural, através de uma identidade territorial atribuída pelos grupos sociais, como forma de 'controle simbólico' sobre o espaço onde vivem (sendo também, portanto, uma forma de apropriação) e uma dimensão mais concreta de caráter político-disciplinar: a apropriação e a ordenação do espaço como forma de domínio e de disciplinarização dos indivíduos (Haesbaert, 2004).

Diante das acepções apresentadas, pretendemos tratar de um rompimento de barragem específico, que gerou o deslocamento de praticamente 600 pessoas do seu território, gerando impacto significativo na vida desses indivíduos, destruindo o tecido social e provocando, assim, a perda dos seus referentes de identidade. Destacamos como o desastre despertou uma vivência do patrimônio perdido nos atingidos, evidenciando que os usos e as apropriações do patrimônio demonstram uma tentativa de reconectar uma identidade destruída, estabelecida por meio da memória coletiva e individual.

A tragédia aqui elencada ocorreu no ano de 2015 na cidade de Mariana, Minas Gerais, mais especificamente no subdistrito de Bento Rodrigues, localizado a $35 \mathrm{~km}$ da cidade. No dia 5 de novembro, por volta das $16 \mathrm{~h}$ e 20 min, a barragem do Fundão, da mineradora Samarco Mineração S.A. - um empreendimento conjunto das maiores empresas de mineração do mundo, a brasileira 
Vale S.A. e a anglo-australiana BHP Billiton -, sofreu uma ruptura e entrou em colapso. Com isto, cerca de 34 milhões de $\mathrm{m}^{3}$ de rejeitos de minério desceram a encosta em direção a Bento Rodrigues (Brito, 2016). $\bigcirc$ enorme volume de rejeitos destruiu completamente o subdistrito de Bento Rodrigues, afetando também os distritos vizinhos de Paracutu de Baixo, Gesteira, Barra Longa e algumas comunidades no distrito de Camargos. Os rejeitos seguiram contaminando os rios Doce, Gualaxo do Norte e do Carmo, chegando até o litoral do Espírito Santo. A maior tragédia ambiental do Brasil deixou 35 cidades de Minas Gerais em situação de emergência ou em calamidade pública, afetando quatro municípios no estado do Espírito Santo.

$\bigcirc$ subdistrito de Bento Rodrigues, também conhecido como comunidade de Bento Rodrigues, devido à sua proximidade com a barragem, foi o primeiro a receber o impacto da onda de rejeitos. A violência da enxurrada foi tão forte que a pequena comunidade desapareceu soterrada pela lama. E com ela, parte de sua história.

Com mais de 300 anos de existência, Bento Rodrigues foi um importante centro de mineração durante o século XVIII, fazendo parte da conhecida rota da Estrada Real ${ }^{1}$. A comunidade abrigava igrejas centenárias com um importante acervo de arte sacra, ruínas arqueológicas, uma rica paisagem natural e toda a imaterialidade figurada na rotina do dia a dia, na dinâmica das relações dos moradores com o espaço, nas tradições locais, nos saberes tradicionais, na tessitura que delimita o ethos do que é ser morador de Bento Rodrigues. A vivência de gerações de famílias e o núcleo existencial de pessoas foram os fatores que tornaram a comunidade de Bento Rodrigues um espaço de memória pulsante.
A lama ocasionou a perda de memórias e identidades. As marcas delimitadas pela tragédia colocaram esses moradores no patamar de atingidos pelo rompimento da barragem e representaram algumas ressignificações na relação destes com o patrimônio perdido, que, agora, se reconstitui por meio de uma memória afetiva, na busca por recompor aquilo que se foi e na tentativa de manter vivas as identidades ligadas ao espaço que já não existe (Figura 1).

Haesbaert (2004) afirma que, em todo processo de "desterritorialização desenraizadora", ocorre um processo inverso de "reterritorialização", espacialmente descontínuo e de maneira complexa (Haesbaert, 2004, p. 1). Nessa lógica, o processo é delimitado por uma realocação de determinada população para um novo lugar, de diferentes condições sociais e econômicas. Pensando na prática de "desterritorialização" dos moradores da comunidade de Bento Rodrigues, o seu processo de "reterritorialização" se deu na cidade de Mariana, a princípio, com as famílias espalhadas pelos hotéis da cidade e posteriormente alocadas em casas alugadas, pagas pela empresa responsável pelo desastre. Esse processo de "reterritorialização" é marcado por uma ruptura da identidade dos atingidos, desenvolvido

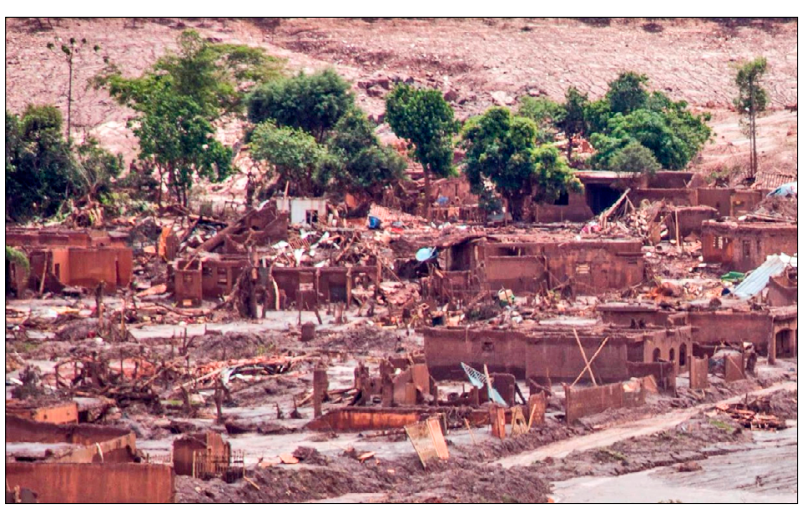

Figura 1. Bento Rodrigues após a passagem dos rejeitos. Foto: Guilherme Weimann/MAB (2017). Fonte: Viana (2017).

\footnotetext{
A Estrada Real é a maior rota turística do país. São mais de 1.630 quilômetros de extensão, passando por Minas Gerais, Rio de Janeiro e São Paulo. A sua história surge em meados do século XVII, quando a Coroa Portuguesa decidiu oficializar os caminhos para o trânsito de ouro e de diamantes de Minas Gerais até os portos do Rio de Janeiro. As trilhas que foram concedidas pela realeza ganharam o nome de Estrada Real (Instituto Estrada Real, n.d.).
}

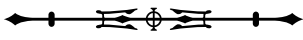


por meio das subjetividades, tanto individuais quanto coletivas, que estão relacionadas aos grupos sociais ligados ao território, estabelecido por uma relação de vizinhança que se perdeu. Em meio a isso, a população de Bento Rodrigues se viu em um território que não diz respeito à sua identidade, como podemos visualizar na fala do atingido Antônio: "Mesmo mudando de casa não nos adaptamos e continuamos procurando nossa identidade, nos ajustando aos padrões" (A Sirene: para não esquecer, 2017, p. 8). No processo de adaptação, ainda lidaram com os diversos preconceitos por parte de alguns moradores da cidade de Mariana² (Figura 2).

A mudança de território trouxe a necessidade, para os atingidos de Bento Rodrigues, de reconfigurarem a maneira como se comunicavam. Na nova luta que se iniciava pela busca dos direitos garantidos ao atingidos, era necessário pensar como reconstruir suas vidas e, nessa dinâmica, manter vivas as memórias identitárias do território destruído. Nesse contexto, foi criado, em janeiro de 2016, três meses após a tragédia, o jornal A Sirene, uma parceria entre os atingidos, a Arquidiocese de Mariana e o Instituto de Ciências Sociais e Aplicadas da Universidade Federal de Ouro Preto (ICSA/UFOP). O jornal foi construído com o intuito de reforçar a autonomia dos atingidos, na mesma medida em que procurou empoderar os mesmos nas suas reivindicações. Conforme consta no editorial da primeira edição do periódico, A Sirene é um jornal feito pelos atingidos e para os atingidos, servindo como ferramenta de apoio para que se preservem as suas memórias e que, a partir deste recurso, se possa reconstruir o elo de identidade rompido no processo de desterritorialização (A Sirene: para não esquecer, 2016, p. 2).

Nesta perspectiva, o presente artigo tem por objetivo debruçar-se - a partir da análise das falas dos

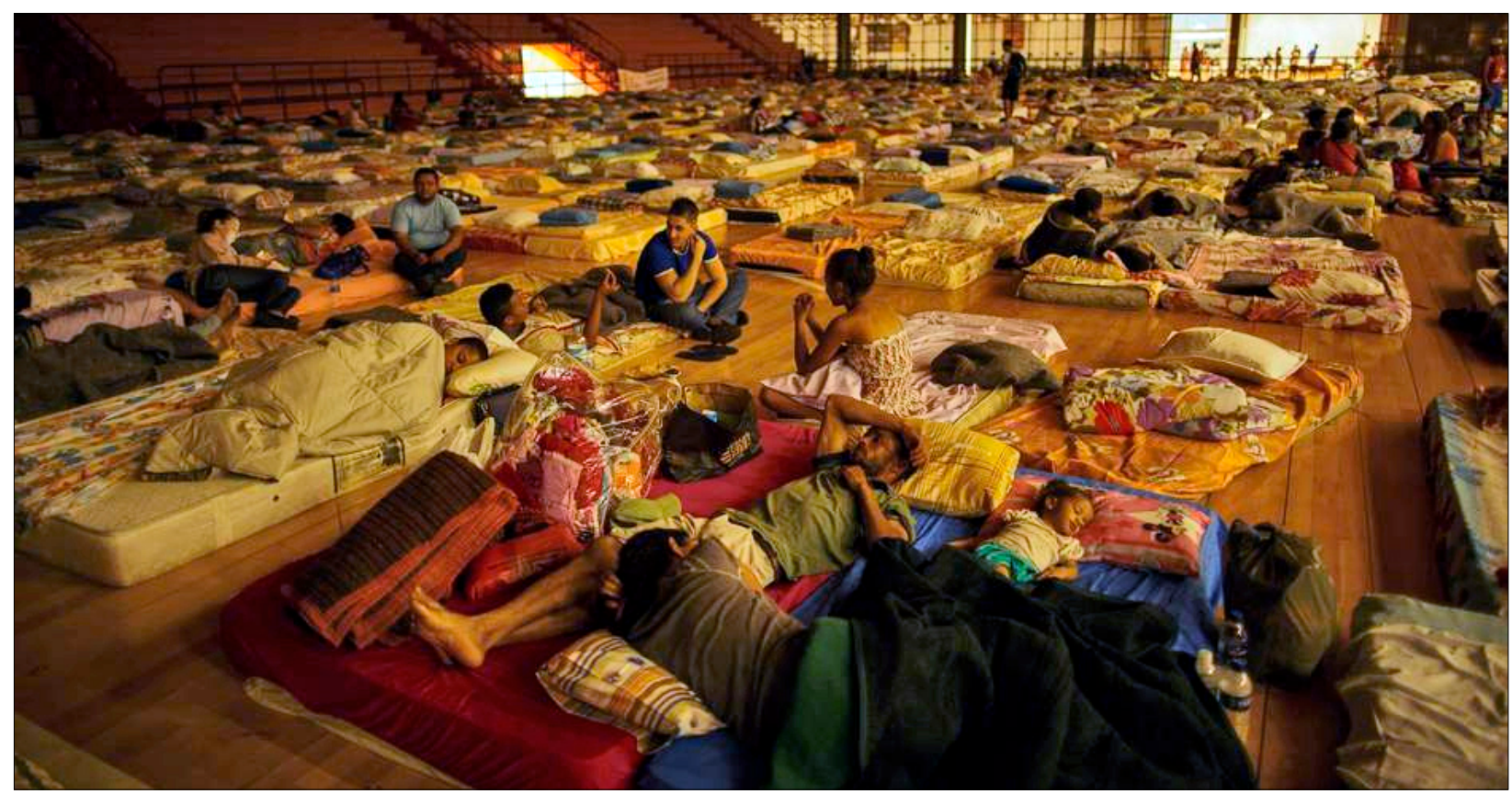

Figura 2. Desabrigados. Vítimas da tragédia em um ginásio da cidade de Mariana. Foto: Daniel Marenco (2015). Fonte: Tinoco \& Sanches (2015).

2 Inúmeros são os relatos que demonstram o preconceito sofrido pelos atingidos na cidade de Mariana. A matéria do jornal Estadão destaca que as crianças eram comumente chamadas de 'pé de lama' na escola, enquanto seus pais eram vistos como 'aproveitadores' porque dependiam da mineração para viver (Ribeiro \& Fernandes, 2016).

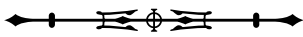


atingidos presentes no jornal A Sirene - sobre como a ideia de patrimônio é usada para construir, reconstruir e negociar as identidades, os valores e os significados sociais e culturais no contexto pós-desastre. $O$ estudo busca, ainda, compreender de que maneira os atingidos medeiam os velhos significados sobre o que representa ser um morador de Bento Rodrigues e entender o 'poder do lugar' no sentido de evocar a emoção ligada ao patrimônio em que a memória e a ideia de pertencimento contribuem para repensar o passado, ao mesmo tempo em que trazem uma expectativa de futuro enraizado nesse passado.

\section{USOS E SENTIDOS DO PATRIMÔNIO NA MANUTENÇÃO DA IDENTIDADE}

Os patrimônios, conforme destaca Gonçalves (2015), nas suas mais variadas formas de categorias, constituem-se como expressão e representação das identidades de grupos e segmentos sociais. A arquitetura, os modos de fazer, as festas, as produções artesanais, as expressões musicais, as paisagens são identificados como "patrimônio cultural" a partir do seu reconhecimento por um grupo, afirmando as identidades. Nessa perspectiva, "Defender, preservar e lutar pelo reconhecimento público desse patrimônio, significa lutar pela própria existência e permanência social e cultural do grupo." (Gonçalves, 2015, p. 213).

Ao nos debruçarmos sobre a fala dos atingidos, notamos como ponto central as observações apresentadas por Gonçalves (2015). Elas expressam uma relação com o patrimônio que define suas identidades. A luta pelo reconhecimento do patrimônio destruído pela lama significa buscar o reconhecimento de suas próprias existências e histórias. A defesa do patrimônio diz respeito à defesa de suas identidades, mantidas pela memória do espaço e pela luta envolvida na celebração de eventos que ocorriam no território destruído. $\bigcirc$ despertar para essa identidade e para esse patrimônio, em certa medida, foi causado pela sensação de perda após o desastre. Isso é ressaltado pelos atingidos Antônio Dalua, Genival Pascoal e Lucimar Muniz, ao destacarem que "É curioso como o rompimento da barragem nos trouxe certos entendimentos, e com eles passamos a valorizar ainda mais o que sempre nos pertenceu, mas não dávamos o devido valor." (Dalua et al., 2017, p. 6). Gonçalves (2015) chama de "consciência de identidade" o processo pelo qual, a partir desse sentimento de perda, os atingidos passaram a se organizar para defender sua cultura e a manutenção do território de Bento Rodrigues, para que ali pudessem ainda estabelecer uma relação de afetividade.

Os atingidos passam a "repovoar o patrimônio", a partir do momento em que buscam falar sobre ele, reintroduzindo os seus protagonismos (Meneses, 2017, p. 41). O patrimônio é, então, compreendido dentro de um processo cultural que envolve atos de recordações trabalhadas a fim de serem criadas maneiras para melhor entender e se engajar no presente (Smith, 2006). Nessa ordem, os locais e os ritos são ferramentas culturais determinantes para a afirmação das identidades. A perda desses referenciais sugere um vazio quanto ao lugar do sujeito no mundo.

Essa percepção pode ser observada na relação que os atingidos mantinham com o padroeiro do subdistrito, São Bento. No primeiro ano após o rompimento da barragem, a realização da festa em homenagem ao padroeiro foi marcada pelo vazio de se realizar a cerimônia em um território cujos atingidos não se sentem pertencentes. A atingida Monica dos Santos destaca esse sentimento:

\begin{abstract}
Por termos perdido todas as nossas referências, principalmente a nossa Capela, a imagem de São Bento e tudo mais, pedimos a Deus coragem para prosseguir e celebramos com muita fé em uma capela emprestada, tomamos as ruas que não eram as nossas com uma imagem doada por irmãos de outra comunidade. (M. Santos, 2016, p. 13).
\end{abstract}

A fala da atingida traz à luz um problema que é pensar como esses moradores, ligados a uma tradição religiosa, irão estabelecer os ritos religiosos, sendo que todas as referências foram perdidas: as imagens dos santos, as igrejas, os percursos. Realizar esse rito com aquilo que 
lhes foi emprestado, que não diz respeito à comunidade, em uma rua que não é deles, desperta, nos atingidos, um senso de pertencimento ao território que se desdobra no sentimento de levar esses ritos para as ruínas de Bento Rodrigues. Embora a comunidade de Bento Rodrigues esteja sob ruínas, ainda é o espaço ao qual os atingidos se sentem pertencentes e, por isso, a aura dos ritos religiosos mantém-se ligada à identidade da comunidade, se realizados no local de origem dessas celebrações.

Tal sentimento fez com que os moradores se engajassem na luta para que as festas religiosas fossem realizadas nos mesmos espaços em que ocorriam antes da tragédia. Dessa forma, no ano de 2016, além da festa realizada em Mariana, os atingidos também fizeram, no dia 30 de julho, a festa de São Bento no território de Bento Rodrigues, com procissão, celebração, queima de fogos e hasteamento da bandeira do padroeiro (Figura 3). Na fala da atingida Lucimar Muniz, "A festa de São Bento, celebrada em Bento Rodrigues, foi um momento importante na nossa luta pelo direito à propriedade." (L. Muniz, 2016, p. 13).

O relato feito pela atingida Lucimar Muniz destaca a relação que os atingidos mantêm com o território perdido. Manter os rituais no espaço destruído é uma maneira de demonstrar que aquele território, apesar de destruído, ainda pertence aos atingidos. Dessa maneira, desde o rompimento da barragem, a festa do padroeiro é

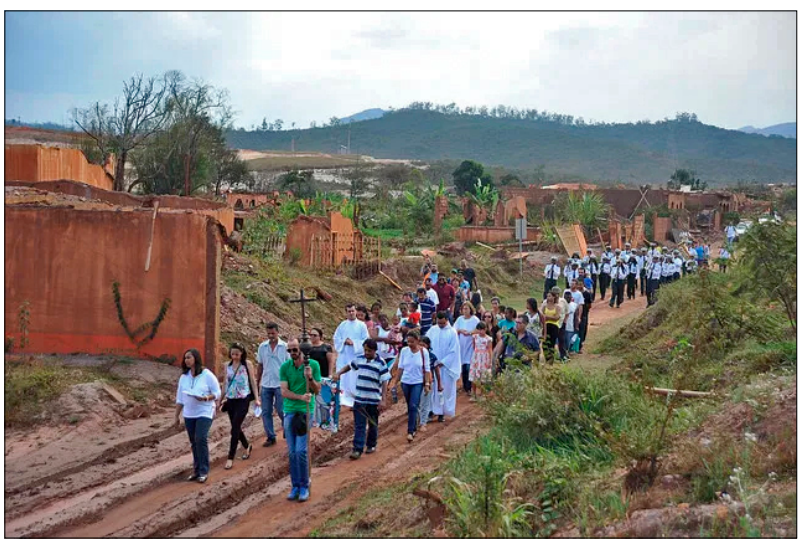

Figura 3. Procissão segue pelas ruínas de Bento Rodrigues para celebrar o dia de São Bento. Fonte: Camargos (2017). realizada sobre as ruínas. A fala da atingida Simária Quintão reforça como os usos do patrimônio para a manutenção da memória serve como mecanismo de resistência para que a história do território destruído não se perca, justamente pela relação que os moradores mantêm com o local:

Não queremos que este lugar morra. A gente vai ter um Bento Rodrigues lá, mas o Bento Rodrigues não vai nascer do nada, ele já existia e existe. Somos uma comunidade antiga e queremos manter as nossas tradições, as nossas festas aqui. Nunca perdemos este lugar. Aqui é a nossa história de vida, nós nascemos e fomos criados neste lugar. (Arquidiocese de Mariana, 2018).

Smith (2006), ao tratar dos usos do patrimônio, demonstra que o patrimônio pode ser entendido como uma importante ferramenta política e cultural na definição e na legitimação da identidade por parte de determinado grupo. Brett (1996 citado em Smith, 2006) argumenta que indivíduos e comunidades são forçados a se articular e recuperar o sentido do passado, afirmando e/ou renegociando o senso de habitus. O uso do patrimônio é essencial nesse processo, principalmente quando se trata de um patrimônio perdido, mas que ainda se configura como representação única da identidade de determinado grupo, como é o caso dos atingidos de Bento Rodrigues. Destarte, não só a ocupação do espaço destruído para manter os ritos religiosos se torna uma ferramenta de recuperação do sentido desse passado que se perdeu, mas também envolve outras ligações afetivas com o espaço determinado pela noção de territorialidade que o patrimônio ocupa.

Como a área atingida pela lama é agora administrada pela Samarco, a luta entre os moradores para terem o direito de manter a sua relação com o espaço é constante. Assim como a própria realização da festa de São Bento, os atingidos buscam também consagrar outros ritos com o território, como o do sepultamento. O falecimento do primeiro atingido após o desastre levantou o debate e as exigências por parte dos atingidos de terem o direito de sepultar os moradores no espaço no qual viveram toda

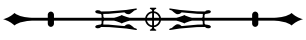


sua vida. Para a atingida Lucimar Muniz, "A festa de São Bento e o sepultamento no território de Bento Rodrigues são formas de continuar uma tradição e de mostrar a quem pertence aquele chão e o que deve ser feito dele." (L. Muniz, 2016, p. 13).

As ruínas de Bento Rodrigues se converteram em 'lugares de memória'. A memória é revivida e ritualizada na tentativa de trazer à vida lembranças cujo meio de acesso se estabelece pela ritualização de uma memória/ história, que investe o 'lugar de memória' de uma "aura simbólica" (Nora, 1993), que, como foi destacado, não se realiza em outro território, se não nas própria ruínas do subdistrito destruído.

Conforme indica Halbwachs (1990), no retorno aos lugares no qual estivemos anteriormente, aquilo que percebemos contribui para a reconstrução de um quadro de memória. $\bigcirc$ que apreendemos dessa lembrança a partir da ritualização com esses 'lugares de memória' é a adaptação de nossas percepções atuais a uma memória passada. No caso de Bento Rodrigues, esse 'lugar' está completamente destruído. Nessa lógica, parece que a reconstituição de um quadro de lembrança se estabelece na reconstrução de uma identidade que se perdeu na destruição dos objetos materiais e imateriais, que servem como aparato de gatilho de uma memória que reforça as identidades. As antigas lembranças, ao se adaptarem às percepções atuais, configuram uma forma de manterem vivas as lembranças vividas que foram destruídas.

As lembranças vão se constituindo a partir da relação que os moradores estabeleciam com o patrimônio nas suas mais diversas categorias. Para Marinalva Salgado, aquelas emergem diante da relação afetiva com a natureza:

A gente tinha vários pés. Era acerola, limão doce, jabuticaba, pitanga. . . . Eu adorava subir no pé de jabuticaba, porque gostoso é subir no pé e panhar a fruta. Agora, a gente tem que comprar, mas não tem o mesmo sabor. (citado em Dores et al., 2018).
As lembranças surgem destacando os aspectos materiais da comunidade:

Tínhamos diversos muros de pedra seca no entorno da Igreja de São Bento, que seguiam por suas ruas, becos e fundos de quintais. São muros que fizeram parte da história de muitas gerações. Estavam ali sempre firmes, até que a lama passou ... (citado em Dalua et al., 2017, p. 13).

Cada elemento de lembrança individual ajuda a reconstruir uma memória coletiva. A reconstrução opera a partir de dados ou noções comuns que se encontram no espírito ${ }^{3}$ dos atingidos. As memórias passam de um indivíduo para o outro, de maneira recíproca, sendo possível essa troca porque são membros de uma mesma comunidade, fazendo com que essas lembranças possam ser, ao mesmo tempo, reconhecidas e reconstruídas (Halbwachs, 1990). Nas memórias, outras lembranças e personagens vão se inserindo:

\begin{abstract}
A galinhada e o feijão português. Feijão vermelho não leva porco, só carne de boi e linguiça. Minha irmã Terezinha que fazia, mas foi Maria que ensinou. Teve uma vez numa virada de ano diferente. Mesa na rua: dona Ducha traz o macarrão, dona Cema traz o que puder trazer. Cada um traz prato de casa. (Quintão, 2016, p. 8).
\end{abstract}

Aquilo que foi destruído pela lama é patrimonializado pelos atingidos, na medida em que os grupos passam a conferir aos objetos reais, ou idealizados, um estatuto particular que os coloca como representativos de suas identidades, tornando-se, assim, elementos operacionais na construção de uma identidade no tempo, estabelecendo, de igual maneira, essa distinção com o 'outro' (Davallon, 2012), configurado como aqueles moradores da cidade de Mariana. Conforme destaca Candau (2011, p. 161), “. . . as representações do patrimônio como bens compartilhados no interior de um grupo particular e como expressão de comunidade específica conduz, muito facilmente, a tentativas de naturalização da cultura, num esforço de enraizamento

\footnotetext{
3 'Espírito' aqui é entendido no sentido metafisico para se referir à consciência ou à personalidade.
}

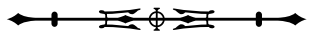


na 'terra natal'”. A conservação de vestígios, relíquias, testemunhos, impressões, serve como reservatório para alimentar as histórias que se constroem a respeito do passado e dá essa "ilusão de continuidade" (Candau, 2011, p. 159), a qual se estabelece mesmo no território deslocado em que se encontram os atingidos pela lama.

\section{EMOÇÕES PATRIMONIAIS: ATOS DE RECORDAÇÃO COMO MECANISMO DE RESISTÊNCIA}

No processo de reconstituição da memória, na relação estabelecida com o patrimônio destruído, é possível perceber um fenômeno que Fabre (2013, p. 21) conceitua como "emoções patrimoniais". Uma emoção que sempre toma conta, perturba, transborda nas estruturas do pensamento e da ação patrimonial. Para Heinich (2013), a emoção parece quase que inseparável da experiência patrimonial. Percebemos que a emoção nos atingidos se torna mais evidente quando essa experiência patrimonial é estabelecida de maneira direta com as ruínas da comunidade de Bento Rodrigues.

A emoção fez com que os atingidos exigissem a participação nos processos de escavações arqueológicas realizados sobre a lama que soterrou o subdistrito. Nesse processo de descoberta, as emoções são constantemente avivadas. Por exemplo, pequenos bancos que estavam soterrados trazem, de maneira instantânea, a emoção despertada pela experiência patrimonial, como o caso experimentado pela atingida Maria, que se emocionou ao encontrar um banco onde costumava se sentar desde criança: "Era o que minha mãe mais queria achar: os bancos de pedra. Foi emocionante! Uma outra vez escavamos no lugar que eles estavam, mas foi em vão. A cada pedra que achávamos que eram os bancos, ela chorava. Foi lindo." (M. Santos, 2017b, p. 7).

As emoções se manifestam não somente na descoberta dos objetos em si, mas na própria experiência de estar sobre as ruínas da comunidade de Bento Rodrigues. Devido à não ruptura dos laços afetivos com o território, o espaço ainda permanece como ativador das emoções, estando situado na relação estabelecida pelos atingidos com as memórias coletivas da comunidade. Parte dessa memória fez com que o casal Marquinhos Muniz e Marinalda Muniz realizassem, no ano de 2017, a comemoração de suas Bodas de Prata na mesma igreja onde se casaram, há 25 anos (Figura 4). Nos seus discursos sobre a celebração, afloram as emoções despertadas pela relação com o objeto patrimonial: "Vivemos a emoção de celebrar as bodas na simplicidade do nosso povoado Bento Rodrigues. Foi nas ruínas da Igreja São Bento, celebração realizada pelo Padre Armando Godinho, e ao lado dos nossos parentes e dos verdadeiros amigos ..." (M. Muniz et al., 2018, p. 9). Nas palavras de Marquinhos,

Aquele lugar, principalmente a Igreja, pra gente é muito valioso. Foi ali que começamos a aprender as coisas. Depois do rompimento da barragem, eu pensei: "perdi a Igreja, esse espaço"; mas hoje em dia eu penso que é muito importante ter celebrado ali, nas ruínas mesmo, no Bento. (citado em M. Muniz et al., 2018, p. 9).

Uma das categorias de emoções patrimoniais está relacionada com o valor de presença das pessoas e a partir dela, no contato com determinados objetos. A sensação de presença traz a emoção que vem do sentimento de insubstituibilidade do objeto na conexão com as pessoas que mantêm uma relação de afetividade com

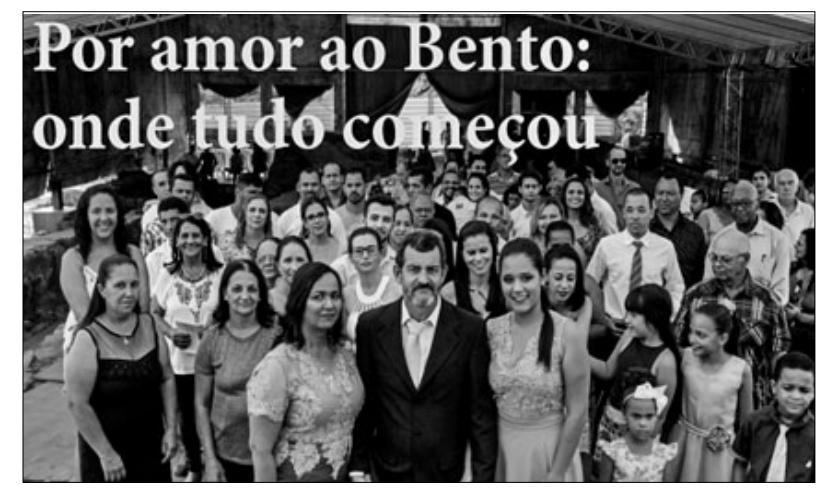

Figura 4. Marquinhos Muniz e Marinalda Ruiz juntos aos convidados na comemoração das bodas de prata realizada nas ruínas da Igreja de São Bento. Foto: Lucas de Godoy (2018). Fonte: M. Muniz et al. (2018, p. 8).

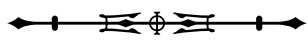


este (Heinich, 2013). Essa presença se faz constante na relação que os atingidos mantêm com as ruínas de Bento Rodrigues, porque é somente a partir desta conexão que eles se sentem ligados a uma identidade única que os define enquanto membros da comunidade.

A categoria de emoção patrimonial, a partir da relação de presença com o objeto - no caso, as ruínas de Bento Rodrigues -, traz à luz as motivações para a criação do grupo denominado 'Loucos por Bentos'. O grupo surge como tentativa por parte dos atingidos de ressignificarem o espaço destruído, ao mesmo tempo em que reforça os laços de afetividades com o local. Nessa lógica, o objetivo do grupo seria se reunir aos fins de semana para acampar nas ruínas de Bento Rodrigues e lá reviver um pouco de sua história, buscando realizar as comemorações que antes faziam parte do cotidiano de cada morador. $O$ depoimento da atingida Maria Quintão destaca a importância desse grupo e o quanto as emoções afloram a partir do contato com o patrimônio identitário dos atingidos:

Sempre que possível, vamos pra lá [Bento] tentando resgatar não as coisas materiais, mas as nossas vidas. Combinamos as nossas ações e sempre nos reunimos nos finais de semana. Das casas que a lama desarrumou, já arrumamos duas. Colocamos portas e janelas naquilo que se tornou o nosso refúgio. A festa de São Bento, de Nossa Senhora das Mercês, o Réveillon, o Carnaval, a Semana Santa, a nossa festa junina, são atos que conseguimos realizar e que nos fizeram nos sentir em casa. Lá, extravasamos o sentimento que fica guardado dentro de nós. Temos, desde o início, o intuito de lutar pela manutenção de nossas tradições e pela recuperação de nossas memórias, que, mesmo soterradas pela lama, são nossas. E também queremos mostrar para o mundo o quanto amamos aquele lugar, onde nascemos e passamos a maior parte das nossas vidas, e que não estamos dispostos a abrir mão dele. Estamos apenas resistindo porque essa luta nos fortalece. Juntos, o nosso grupo "Loucos pelo Bento" pretende vencer com a ajuda de Deus, pois a nossa fé é o que nos dá força. (citado em Pascoal et al., 2017, p. 5).
A fala da atingida Maria Quintão demonstra a importância das emoções patrimoniais na luta para a preservação não só das tradições, mas do próprio espaço, porque é a partir dele que os atingidos mantêm uma relação viva com a memória da comunidade. Embora a emoção patrimonial, quando manifestada, seja entendida naturalmente de maneira positiva, ela também possui um caráter negativo, segundo Heinich (2013). Para a autora, essas emoções são essencialmente defensivas: são aquelas que visam manter vivos determinados objetos passíveis de destruição. Essas ações emocionais pressionam por uma ação, principalmente quando existe um culpado que pode ser designado como o motivador da destruição desses objetos patrimoniais (Heinich, 2013). A mistura de lamentações e acusações é o princípio de mobilizações, no sentido de proteger determinado bem de sua completa destruição.

A ideia negativa da emoção patrimonial na defesa do patrimônio expressa uma destacada articulação dos atingidos de Bento Rodrigues na proteção daquilo que restou da comunidade. Isso porque, no ano de 2016, a mineradora Samarco afirmou ser necessária a construção de um dique para evitar o carreamento de rejeitos de mineração da barragem do Fundão, bem como outros problemas durante o período chuvoso ${ }^{4}$. A justificativa é a de que, com o dique, os impactos dos rejeitos que ainda se mantiveram na barragem do Fundão seriam reduzidos. Porém, a construção desse dique promoveria o alagamento de parte das ruínas de Bento Rodrigues, o que gerou o descontentamento dos atingidos, que se mobilizaram para evitar que, mais uma vez, parte de suas memórias fosse soterrada. Para os atingidos, o alagamento das ruínas seria uma forma de apagar não somente a sua memória, mas também a própria memória da tragédia. A mobilização se estabeleceu no sentido de perceber outras dinâmicas de proteção do patrimônio, no caso em específico, de recorrer à proteção oficial a fim de

\footnotetext{
4 Segundo a Samarco, a construção do dique S4 integraria o ". . . sistema emergencial de retenção de sedimentos composto pelos diques S1, S2 e S3, além das barragens Eixo 1 de Fundão e Nova Santarém. Ele será feito por um alteamento com pedras construído, em recuo já existente, um pouco abaixo de Bento Rodrigues, e ampliará a chamada área de clareação dos rejeitos. Isso evitará, na avaliação da mineradora, que a poluição volte a atingir o rio Gualaxo e, consequentemente, o rio Doce." (Vale, 2016).
}

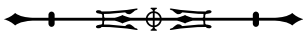


evitar o alagamento. $\bigcirc$ tombamento do subdistrito surgiu como a única maneira de evitar a destruição completa de seus territórios, o que engajou os atingidos a realizarem um abaixo-assinado para que o local fosse tombado no âmbito municipal. Eles, assim, tomam consciência da importância do tombamento e da representatividade do espaço para não se esquecerem da tragédia.

Essas ruas que sobraram serviram de rota para quem teve de correr e não ser levado pela lama. Essas casas que sobraram serviram de abrigo para passarmos a última noite. Elas são essenciais para manutenção da nossa memória como comunidade, pois também contam o fato ocorrido no dia do rompimento. (A. Santos, 2017b, p. 19).

\section{Para Genival Pascoal,}

O tombamento vai fazer com que tudo aquilo que a gente viveu um dia não seja apagado de nossa memória. Sabemos das dificuldades que vamos enfrentar para conseguir o tombamento, mas depois que conseguir, vai ser melhor porque não vamos precisar ficar com aquela preocupação da empresa destruir tudo aquilo que sobrou (citado em Paranhos \& Pascoal, 2017, p. 25).

A mobilização ocasionou a realização de audiência pública, ocorrida no dia 19 de abril de 2016, na qual o Conselho Municipal do Patrimônio Cultural de Mariana (COMPAT), após ouvir os moradores de Bento Rodrigues, confirmou que daria início ao processo de tombamento das comunidades atingidas pela barragem do Fundão (Assessoria de Impressa da Prefeitura de Mariana, 2016). $\bigcirc$ processo se estendeu por longos meses, sem que fosse obtido nenhum resultado efetivo. Somente no ano de 2018, o tombamento estadual da Capela de Nossa Senhora das Mercês foi aprovado pela Deliberação CONEP 19/2018, de 17 de outubro de 2018, e inscrito nos Livros do Tombo II - de Belas Artes - e III - Histórico, das Obras de Arte Históricas e dos Documentos Paleográticos ou Bibliográficos (Instituto Estadual do Patrimônio Histórico e Artístico de Minas Gerais, n.d.).

Em relação ao tombamento municipal, nada foi efetivado, estando ainda em processo de avaliação devido à complexidade que envolve o tombamento de um distrito inteiro, o que requer muita discussão (Nassif, 2018). Porém, essa mobilização levantou outra questão no que diz respeito ao que será feito das ruínas de Bento Rodrigues. Os atingidos serão reassentados em um novo espaço, no que hoje é chamado de 'Novo Bento'. Mas as novas propriedades não tiram o direito que os atingidos possuem sobre as antigas áreas, as quais hoje são apenas ruínas. Ou seja, eles próprios é que devem decidir qual será o destino dado a essas áreas.

Nesse debate, entra em discussão a necessidade de se preservar a memória do distrito e do próprio rompimento da barragem, que levou à completa destruição do local. As discussões que se estabeleceram desde a mobilização para o tombamento da comunidade indicam que o local deveria se tornar um centro de memória ou museu de território (Rodrigues, 2016). Nada foi concretizado quanto ao destino que será dado às ruínas. A mobilização fez com que somente parte do distrito fosse inundada pelo dique S4, preservando as ruínas, única forma de contato dos atingidos com os objetos cuja emoção patrimonial despertada reforçou a luta pela preservação desse espaço.

\section{O “NOVO BENTO”: TEMPO, MEMÓRIA E APROXIMAÇÕES COM O PASSADO}

No processo de deslocamento causado pelo rompimento da barragem, em meio à reparação da tragédia, os atingidos tomaram consciência de que seriam reassentados em uma outra localidade, cujo espaço, como foi dito, é denominado de 'Novo Bento'. Diante dessa ideia do 'novo', o que se destaca é como eles lidam temporalmente com o passado na dinâmica que envolve pensar de que maneira será estruturado esse futuro. Nessa lógica, o passado, nos apoiando em Koselleck (2006), é pensado como 'espaço de experiência' que reforça a identidade dos atingidos, e é acionado possibilitando a percepção de que, nesse 'horizonte de expectativa', o futuro, a vivência no 'Novo Bento', seria marcado por uma experiência pretérita que surge como aquela que deve ser resgatada. Koselleck (2006), ao procurar definir as categorias meta-históricas, considera 
a experiência como sendo os acontecimentos do passado que são incorporados e podem ser lembrados no presente. passado, nesse sentido, é transmitido a cada geração, e desenvolve, nos indivíduos, determinados comportamentos que presentificam o passado. Nesse processo, as memórias (re)vividas pelos atingidos nas permanências são marcadas por um sentimento de que o presente enquanto experiência temporal não é experimentado, tendo em vista que não consideram como seu o espaço que agora ocupam, restando somente esse 'espaço de experiência', que se configura na proteção da cultura da comunidade, em que o patrimônio emerge como ferramenta identitária dos atingidos.

$\mathrm{O}$ passado é experimentado a todo momento e surge como o lugar que deve ser restaurado no 'Novo Bento'. Essas experiências são expressas nos sentimentos dos moradores quando revelam a expectativa quanto ao novo espaço: "Não há nada que substitua a nossa vida em nossa origem. Tudo o que queremos é trazer um pouco de nossa história para podermos viver o pouco dela que ainda resta em nossa mente (Genival)" (citado em A. Santos \& Pascoal, 2017, p. 9). Para a atingida Hiata Meiriane Salgado, que estava com seis meses de gravidez no dia da tragédia, surgia o desejo de transmitir aos filhos as memórias com o intuito de manter a identidade da comunidade naqueles que não viveram nesse território: "Quero passar para os meus filhos as boas experiências que tivemos no antigo Bento, porque quando o novo Bento sair eles vão estar bem grandinhos, para que as histórias que nós vivemos no Bento não morram." (citado em M. Santos, 2017a, p. 13).

Imerso na reconstrução do passado, o presente surge como um tempo suspenso, figurando um movimento de rememoração desse passado, cuja expectativa é a do retorno daquilo que foi vivenciado. Esse retorno se configura como a própria relação de vizinhança que era estabelecida entre os atingidos, conforme destaca Mauro Marcos da Silva: "A gente não quer um Bento lindo e maravilhoso, a gente quer um Bento mais parecido com o antigo e principalmente manter a relação de vizinhança." (citado em Carvalho, 2018, p. 4). Outro atingido manifesta a mesma vontade apresentada por Mauro Marcos: "A maioria tem o mesmo objetivo: viver num cantinho, sossegado, na rocinha lá, com os mesmos vizinhos, todo mundo unido, do mesmo jeito." (citado em Atingidos do Bento, 2016, p. 9).

Estabelecer a relação de vizinhança, na concepção dos atingidos, possibilitará a manutenção das relações de afetividades, reabilitando o tecido social da comunidade. Esse pensamento fez com que os atingidos recusassem o projeto urbanístico do 'Novo Bento' apresentado pela Fundação Renova ${ }^{5}$, por não respeitar as disposições das casas, das igrejas, das escolas e das praças, tal qual eram no antigo subdistrito. $\bigcirc$ projeto não levava em consideração os anseios dos atingidos, que exigiram a participação na sua elaboração. Segundo o atingido Antonio Geraldo dos Santos,

\begin{abstract}
. . . na elaboração e execução desse projeto é fundamental a nossa participação. Somos nós que iremos frequentar as praças e não podemos deixar o arquiteto fazer tudo do seu jeito, muito menos permitir que alguém defina o modelo de nossas casas sem antes nos consultar. $E$ a dificuldade não se restringe às casas e ruas, mas também ao modo de vida das comunidades. Laços terão que ser refeitos num lugar totalmente diferente e não há técnico que consiga refazer uma comunidade com a nossa identidade sem entender o contexto em que vivíamos. Somente os atingidos são capazes de trazer esses elementos de volta [ênfase adicionada] (A. Santos, 2017a, p. 8).
\end{abstract}

A partir desse movimento, o novo projeto apresentado, com a participação dos atingidos, foi elaborado no sentido de manter as mesmas relações de vizinhanças estabelecidas no antigo Bento ${ }^{6}$. A própria escolha do terreno onde será construído o 'Novo Bento' se deu

\footnotetext{
5 A Fundação Renova é a entidade responsável pela mobilização para a reparação dos danos causados pelo rompimento da barragem de Fundão, em Mariana, Minas Gerais. Trata-se de uma organização sem fins lucrativos, resultado de um compromisso jurídico chamado Termo de Transação e Ajustamento de Conduta (TTAC). Ele define o escopo da atuação da Fundação Renova, que são os 42 programas que se desdobram nos muitos projetos que estão sendo implementados nos 670 quilômetros de área impactada ao longo do rio Doce e de seus afluentes (Fundação Renova, n.d.a).

6 Ver Fundação Renova (n.d.b).
}

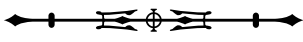


mediante a participação dos atingidos. Ela revela a vontade destes de se manterem conectados com aquilo que sobrou do antigo Bento, no desejo de utilizar os mesmos espaços como forma de manter vivas suas identidades. $\bigcirc$ terreno foi escolhido pelo atingido Zezinho Café, por se encontrar na rota que leva ao antigo terreno de Bento Rodrigues. Embora outros dois terrenos tenham sido sugeridos, o escolhido por Zezinho Café foi aprovado por 95\% dos atingidos ${ }^{7}$. O terreno conhecido como Lavoura fica a $9 \mathrm{~km}$ do antigo Bento. Para os atingidos, a proximidade é uma forma de manter os laços de afetividade, uma maneira de vivenciar os espaços vinculados à identidade determinada pela relação com os referentes patrimoniais, como destaca um dos atingidos: "Pelo menos lá (no sentido do Bento) dá pra gente continuar a ir nos lugares que a gente ia antes." (Atingidos por Bento, 2016, p. 8).

A manutenção dessa relação com o antigo território é um importante processo para a adaptação no 'Novo Bento'. Além disso, sua escolha reflete a consciência dos atingidos acerca das diferentes dinâmicas do que é morar na cidade e do que é morar no campo. Por isso, o reassentamento perto da cidade de Mariana nunca foi do interesse dos atingidos, local onde hoje se encontram 'desterritorializados', por terem consciência de que o 'Novo Bento' não seria mais um distrito, e sim um bairro: "Se fizesse pro lado de cá (da sede de Mariana), não ia ser mais um distrito, ia ser um bairro. E a gente não queria ser bairro de Mariana." (Atingidos por Bento, 2016, p. 8).

O dilema que se coloca, a partir do cenário pós-desastre, é como se dará a ocupação desse novo espaço e de que maneira serão estabelecidas as novas construções históricas nesse novo território. As narrativas dos atingidos expressam um desejo de retorno a partir do constante contato com os bens patrimoniais destruídos pela lama. Mas de que maneira esses bens se apresentarão nesse 'Novo Bento'?
Riegl (1984) destaca que os bens patrimoniais podem apresentar diferentes valores de memória, como: o valor de antiguidade, que marca a passagem do tempo; o valor de comemoração, que expressa um desejo de continuidade na retomada de um passado; e o bem de valor histórico, que atua como prova de um passado do qual fez parte. Embora os atingidos lutem para que se mantenham as mesmas relações afetivas no 'Novo Bento', esses novos bens patrimoniais que surgirão com este espaço encontrar-se-ão vazios de valores, porque a construção coletiva do passado se baseia na referência estabelecida com o 'velho' Bento, e não com o 'novo'.

As identidades dos atingidos encontram-se enraizadas nas ruínas do antigo Bento. As ruínas, por si só, têm a natureza de retorno a um passado perdido e funcionam como ferramenta que possibilita a imersão no passado ligado a ela, bem como o entendimento desse passado. As ruínas de Bento Rodrigues são o registro histórico de outros tempos que se perderam e que não voltarão mais a existir. Cumpre o seu papel de testemunho e de narrar parte da história da tragédia e dos seus desdobramentos que se seguirão no 'Novo Bento'. Como lugar de memória, carrega em si uma carga simbólica do patrimônio da comunidade de Bento Rodrigues, capaz de proporcionar uma 'volta' ao passado.

\section{CONSIDERAÇÕES FINAIS}

Este artigo foi levado a cabo a partir do entrecruzamento das noções de emoções patrimoniais, usos do patrimônio, nostalgia do patrimônio e lugares de memória, presentes nas ações dos atingidos, mediante à luta por reparação que se estabeleceu a partir da tragédia. Consideramos estes elementos como constituintes fundamentais para a compreensão de como os atingidos de Bento Rodrigues se mobilizaram a partir de um entendimento de patrimônio despertado pela perda do território, servindo como mecanismo de reivindicação de direito à memória.

\footnotetext{
7 Ver Fundação Renova (n.d.c).
} 
Lugar para a memória, as ruínas de Bento Rodrigues expõem os registros da vida e da trajetória social e histórica dos atingidos, incididos sob a luz do patrimônio na reconfiguração do tempo e sentidos na ressignificação de suas identidades. A ligação com as ruínas desperta variadas formas de emoções patrimoniais, ora atreladas ao aspecto da autenticidade que se concentra na continuidade do vínculo entre o estado atual do patrimônio destruído na relação com a sua origem; ora com a emoção da presença, na dinâmica da proximidade estabelecida entre os atingidos junto aos bens patrimoniais; ora em relação com a beleza, ligada ao valor estético que o território destruído ainda representa (Heinich, 2013). Todos esses sentimentos são amplificados pela emoção frente às ruínas, que se liga aos lugares de memória, reforçando a presença do passado.

Após mais de quatro anos da tragédia, a construção do 'Novo Bento' ainda é uma incógnita para os atingidos. Eles ainda permanecem 'desterritorializados' e em meio às disputas em torno da manutenção da memória ligada ao espaço patrimonial destruído, mas que ainda permanece vivo na sua intangibilidade, nos discursos e nas práticas que se ressignificam e se valorizam por meio da sociabilidade e da sensibilidade no contato com os bens patrimoniais identitários (Smith, 2006). O rompimento da barragem causou inúmeras perdas que levarão anos para serem reparadas; algumas delas jamais serão restituídas. A grande dúvida que se coloca é sobre como serão estabelecidas as relações afetivas, de identidade, que os atingidos identificam nesse passado, mas que se reconfigura no presente, e podem gerar outras formas de socialização no futuro.

É necessário, nesse processo de reassentamento, o estabelecimento de uma política de patrimônio que reconstrua a memória coletiva dos atingidos pelo rompimento da barragem, no intuito de visibilizar, referenciar e dar significado a esse grupo que constantemente luta pelo direito ao passado, na manutenção das identidades. Tal perspectiva coloca-se da mesma maneira com os usos que se pretende dar às ruínas do antigo Bento Rodrigues, pois o dever de memória é uma forma de reparação diante do desastre decorrente de ações relacionadas ao meio ambiente. Deve-se reforçar o não esquecimento, colocando os atingidos como os principais agentes na busca deste reconhecimento.

\section{REFERÊNCIAS}

Arquidiocese de Mariana. (2018, julho 30). Atingidos celebram a festa de São Bento em Bento Rodrigues. Recuperado de http:// saosebastiaopn.com.br/noticia/atingidos-celebram-a-festa-desao-bento-em-bento-rodrigues/

Assessoria de Impressa da Prefeitura de Mariana. (2016, abril 20). Conselho do Patrimônio de Mariana decide pelo tombamento de Bento Rodrigues e Paracatu de Baixo. Hoje em Dia. Recuperado de https://www.hojeemdia.com.br/ horizontes/conselho-do-patrim\%C3\%B4nio-de-marianadecide-pelo-tombamento-de-bento-rodrigues-e-paracatude-baixo-1.378031/

A Sirene: para não esquecer. (2016, fevereiro). Recuperado de https://issuu.com/jornalasirene/docs/sirene_final_diogo_bx

A Sirene: para não esquecer. (2017, fevereiro). Recuperado de https://issuu.com/jornalasirene/docs/a_sirene_fevereiro_issuu

Atingidos por Bento. (2016, junho). A lavoura perto do Bento. A Sirene: para não esquecer. Recuperado de https://issuu.com/ jornalasirene/docs/a_sirene_ed3_junho_issuu

Brett, D. (1996). The construction of heritage. Cork: Cork University Press.

Brito, P. (2016, setembro). Paisagem relíquia formada por acidente de causas antrópicas: o caso de Bento Rodrigues. In Colóquio IberoAmericano Paisagem Cultural, Patrimônio e Projeto. Universidade Federal de Minas Gerais, Belo Horizonte.

Camargos, D. (2017, novembro 2). Loucos por Bento Rodrigues: dois anos após o desastre de Mariana, ex-moradores ainda frequentam as ruínas arrasadas pela lama e se negam a trocar os destroços por novas casas. Revista Piauí. Recuperado de https:// piaui.folha.uol.com.br/loucos-por-bento-rodrigues/

Candau, J. (2011). Memória e identidade (M. L. Ferreira, Trans.). São Paulo: Contexto.

Carvalho, J. (2018, julho). A angústia da espera. A Sirene: para não esquecer. Recuperado de https://issuu.com/jornallampiao/ docs/lampi_o_32

Dalua, A., Pascoal, G., \& Muniz, L. (2017, janeiro). Muros antigos de Bento. A Sirene: para não esquecer. Recuperado de https:// issuu.com/jornalasirene/docs/a_sirene_ed_10_janeiro_issuu 
Davallon, J. (2012). Comment se fabrique lepatrimoine: deux régimes de patrimonialisation. In C. Khaznadar (Coord.), Le patrimoine, oui, mais quel patrimoine? (pp. 41-58). Paris: Maison Desculturesdu Monde.

Dores, M., Quintão, M. G., Salgado, M., Quintão, M., Santos, S. N., \& Santos, W. E. (2018, janeiro). Nossas histórias debaixo dos pés de frutas. A Sirene: para não esquecer. Recuperado de https:// issuu.com/jornalasirene/docs/asirene_ed22_janeiro_issuu

Fabre, D. (2013). Le patrimoineporté par l'émotion. In D. Fabre (Ed.), Émotions patrimoniales (pp. 13-100). Paris: Éditions de la Maison des Sciences de l'Homme.

Fundação Renova. (n.d.a). A Fundação. Recuperado de https://www. fundacaorenova.org/a-fundacao/

Fundação Renova. (n.d.b). Reconstrução de Bento Rodrigues: Projeto Urbanístico. Recuperado de https://www.fundacaorenova. org/wp-content/uploads/2017/04/complemento-4_projetourbanistico-de-bento-rodrigues.pdf

Fundação Renova. (n.d.c). Histórias no Caminho da Reparação-Zezinho Café. Recuperado de https://www.caminhodareparacao.org/ historias-no-caminho-da-reparacao-zezinho-cafe/

Gonçalves, J. R. S. (2015). O mal-estar no patrimônio: identidade, tempo e destruição. Estudos Históricos, 28(55), 211-228. doi: http://dx.doi.org/10.1590/S0103-21862015000100012

Haesbaert, R. (2004, setembro). Dos múltiplos territórios à multiterritorialidade. In Seminário Nacional sobre Múltiplas Territorialidades, Universidade Federal do Rio Grande do Sul, Porto Alegre.

Halbwachs, M. (1990). A memória coletiva (L. L. Schaffter, Trans.). (2 ed.). São Paulo: Revistas dos Tribunais.

Heinich, N. (2013). Esquisse d'une typologie des émotions patrimoniales. In D. Fabre (Ed.), Émotions patrimoniales (pp. 195-212). Paris: Éditions de la Maison des Sciences de l'Homme.

Instituto Estadual do Patrimônio Histórico e Artístico de Minas Gerais. (n.d.). Capela de Nossa Senhora das Mercês. Recuperado de http://www.iepha.mg.gov.br/index.php/programas-e-acoes/ patrimonio-cultural-protegido/bens-tombados/details/1/145/ bens-tombados-capela-de-nossa-senhora-das-mercês

Instituto Estrada Real. (n.d.). História. Recuperado de http://www. institutoestradareal.com.br/estradareal

Koselleck, R. (2006). Futuro passado: contribuição à semântica dos tempos históricos (W. P. Maas \& C. A. Pereira, Trans., C. Benjamin, Rev. ed.). Rio de Janeiro: Contraponto.

Meneses, U. T. B. (2017). Repovoar o patrimônio ambiental urbano. Revista do Patrimônio e Histórico e Artístico Nacional, (36), 39-52. Recuperado de http://portal.iphan.gov.br/ publicacoes/lista?categoria $=23 \&$ busca
Muniz, L. (2016, agosto). Acolhida, esperança e resistência. A Sirene: para não esquecer. Recuperado de https://issuu.com/ jornalasirene/docs/asirene_ed5_agosto_issuu

Muniz, M. R. S., Muniz, M. A. S., Muniz, M. M., \& Santos, M. (2018, janeiro). Por amor ao Bento: onde tudo começou. $A$ Sirene: para não esquecer. Recuperado de https://issuu.com/ jornalasirene/docs/asirene_ed22_janeiro_issuu

Nassif, L. (2018, novembro 6). Moradores decidirão futuro de distritos atingidos pela lama em Mariana. O Jornal de Todos os Brasis. Recuperado de https://jornalggn.com.br/movimentossociais/moradores-decidirao-futuro-de-distritos-atingidospela-lama-em-mariana/

Nora, P. (1993). Entre memória e história: a problemática dos lugares. Projeto História, (10), 7-28.

Paranhos, C., \& Pascoal, G. (2017, fevereiro). Tombamento parado na Prefeitura há 9 meses. A Sirene: para não esquecer. Recuperado de https://issuu.com/jornalasirene/docs/a sirene_fevereiro_issuu

Pascoal, G., Muniz, F. R. M., Quintão, M., \& D’Ângelo Júnior, M. (2017, julho). Direitos rompidos. A Sirene: para não esquecer. Recuperado de https://issuu.com/jornalasirene/ docs/a_sirene_ed._16_julho_issuu

Quintão, S. (2016, março). Sabores da memória. A Sirene: para não esquecer. Recuperado de https://issuu.com/jornalasirene/ docs/asirene2sm

Ribeiro, B., \& Fernandes, M. (2016, outubro 29). Desabrigados pela lama enfrentam preconceito e desconfiança em Mariana. Estadão. Recuperado de https://brasil.estadao.com.br/noticias/ geral,desabrigados-pela-lama-enfrentam-preconceito-edesconfianca-em-mariana, 10000085277

Riegl, A. (1984). Le culte moderne des monuments: son essence et sa genèse (D. Wieczorek, Trans.). Paris: Seuil.

Rodrigues, L. (2016, maio 5). Distritos vão virar museu para que a tragédia de Mariana não seja esquecida. Agência Brasil. Recuperado de http://agenciabrasil.ebc.com.br/geral/ noticia/2016-05/distritos-vao-virar-museu-para-que-tragediade-mariana-nao-seja-esquecida

Santos, M. (2015). $O$ conceito de atingido por barragens-direitos humanos e cidadania. Revista Direito e Práxis, 6(11), 113-140. doi: https://doi.org/10.12957/dep.2015.12698

Santos, M. (2016, agosto). Acolhida, esperança e resistência. A Sirene: para não esquecer. Recuperado de https://issuu.com/ jornalasirene/docs/asirene_ed5_agosto_issuu

Santos, M. (2017a, fevereiro). Mães da esperança. A Sirene: para não esquecer. Recuperado de https://issuu.com/jornalasirene/ docs/a sirene fevereiro issuu 
Santos, M. (2017b, janeiro). Memória e espaço. A Sirene: para não esquecer. Recuperado de https://issuu.com/jornalasirene/ docs/a_sirene_ed_10_janeiro_issuu

Santos, A. G. (2017a, março). De atingido para atingido: reconstrução. A Sirene: para não esquecer. Recuperado de https://issuu.com/ jornalasirene/docs/a_sirene_mar_o_ed12_issuu

Santos, A. G. (2017b, fevereiro). As ruas que sobraram. A Sirene: para não esquecer. Recuperado de https://issuu.com/jornalasirene/ docs/a_sirene_fevereiro_issuu

Santos, A. G., \& Pascoal, G. (2017, fevereiro). Intimidade provisória. A Sirene: para não esquecer. Recuperado de https://issuu.com/ jornalasirene/docs/a sirene fevereiro issuu

Silva, V. P., \& Silva, R. G. S. (2011). Os atingidos por Barragens: reflexões e discussões teóricas e os atingidos do assentamento Olhos D'água em Uberlândia-MG. Sociedade e Natureza, 23(3), 397-408.

Smith, L. (2006). Uses of Heritage. Routledge: Oxford.

Taddei, R. (2016, março 10). Os desastres em uma perspectiva antropológica. Com Ciência: Revista Eletrônica de Jornalismo Científico. Recuperado de http://www.comciencia.br/ comciencia/handler.php? section $=8 \&$ edicao $=121 \& i d=1469$
Tinoco, D., \& Sanches, M. (2015, novembro 6). 'Parecia que o mundo estava acabando' diz sobrevivente em MG. O Globo. Recuperado de https://oglobo.globo.com/brasil/ parecia-que-mundo-estava-acabando-diz-sobrevivente-emmg-1-17979495

Vainer, C. B. (2008). Conceito de "atingido": uma revisão do debate. In F. D. Rothman (Ed.), Vidas alagadas: conflitos socioambientais, licenciamento e barragens (pp. 39-63). Viçosa, MG: UFV.

Vale, J. H. (2016, setembro 21). Governo libera construção de novo dique da Samarco em Bento Rodrigues, Mariana. Jornal Estado de Minas Gerais. Recuperado de https://www.em.com. br/app/noticia/gerais/2016/09/21/interna gerais,806338/ governo-libera-construcao-de-novo-dique-da-samarco-emmariana.shtml

Viana, A. (2017, novembro 5). Rio doce: a lama oculta. OutrasPalavras. Recuperado de https://outraspalavras.net/ mercadovsdemocracia/rio-doce-a-tragedia-oculta/

\section{CONTRIBUIÇÃO DOS AUTORES}

A. F. Silva contribuiu com conceituação, investigação, metodologia e escrita (rascunho original e revisão e edição) e P. Faulhaber atuou na liderança das tarefas de conceituação, investigação e escrita (revisão e edição), bem como contribuiu na metodologia e na supervisão. 
